\title{
Physician-Diagnosed Obesity in German 6- to 14-Year-Olds
}

\section{Prevalence and Comorbidity of Internalising Disorders, Externalising Disorders, and Sleep Disorders}

\author{
Heike Eschenbeck $^{\mathrm{a}} \quad$ Carl-Walter Kohlmann $^{\mathrm{a}} \quad$ Stefan Dudey $^{\mathrm{b}} \quad$ Thomas Schürholz $^{\mathrm{b}}$ \\ a Department of Psychology, University of Education Schwäbisch Gmünd,

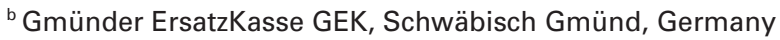

\section{Key Words}

Obesity - Mental health · Community-based sample .

Children · Adolescents

\begin{abstract}
Summary
Objective: This study analyses whether children with obesity have an increased risk of internalising disorders, externalising disorders, and sleep disorders compared to children without physician-diagnosed obesity. Method: The study included 156,948 children aged between 6 and 14 years. We analysed data of a German national health insurance company concerning the rates of the physician-diagnosed ICD-10 disorders of obesity and psychiatric disorders. Results: Greater odds for externalising disorders (odds ratio $(O R)=1.64$ ), internalising disorders $(O R=2.00)$, sleep disorders $(O R=1.87$ ), and a stay in hospital (OR $=1.44$ ) were found among children with physician-diagnosed obesity compared to children without physician-diagnosed obesity. The increased ORs were higher in girls with obesity compared to boys with obesity for externalising disorders $(O R=1.91$ vs. 1.52) and internalising disorders (especially anxiety, $O R=2.15$ vs. 1.43). According to age group, the increased OR was highest in young adolescents (12- to 14-year-olds) with obesity compared to younger children with obesity for internalising disorders (especially anxiety, $\mathrm{OR}=2.32$ vs. 1.59 and 1.43). Conclusion: For obesity prevention and obesity intervention, it is important to understand comorbid health problems as well as potential interindividual influence factors (such as gender or age), both of which should be a focus in respective programmes.
\end{abstract}

\section{Introduction}

Obesity is recognised as a major public health epidemic $[1,2]$. In childhood, overweight and obesity is a prevalent and increasing health problem [3]. For German children and adolescents aged $3-17$ years, the prevalence of overweight is 15 and $6.3 \%$ for obesity [4].

Obesity in childhood is associated with medical consequences in childhood and adolescence and is also a risk factor for diseases in adulthood [5, 6]. Moreover, obesity in childhood is associated with negative psychological consequences [7, 8]. The effects of child and young adolescent overweight and obesity on poorer (health-related) quality of life (assessed by paediatric quality of life questionnaires) and psychosocial well-being were documented in clinical samples [9-11] and, to a smaller extent, in community-based samples [12-14].

Exploring the frequency of mental disorders (according to DSM-IV criteria [15]), Vila et al. [16] showed that internalising problems (i.e. behaviours that deal with problems within the person such as anxiety disorders and affective disorders) and externalising problems (i.e. behaviours directed outward such as disruptive behaviour, including attention deficit hyperactivity disorder (ADHD)) were frequent in 155 obese out-patients. More specifically, 63 children and adolescents had at least an anxiety disorder, 19 had an affective disorder, and 25 had a disruptive behaviour disorder.

With regard to externalising disorders, Agranat-Meged et al. [17] showed a higher risk of ADHD (assessed by clinical evaluation) for children hospitalised for obesity compared to the general population. Holtkamp et al. [18] reported that the prevalence of overweight and obesity in a clinical sample of boys with ADHD (assessed by clinical evaluation) was higher than the age-adapted reference values of the German popula-

\begin{tabular}{ll}
\hline KARGER & @ 2009 S. Karger GmbH, Freiburg \\
Fax +497614520714 & Accessible online at: \\
Information@Karger.de & www.karger.com/ofa \\
www.karger.com &
\end{tabular}


Table 1. Participant characteristics

\begin{tabular}{|c|c|c|c|c|c|c|}
\hline \multirow[t]{3}{*}{ Age group, years } & \multicolumn{6}{|c|}{ Diagnosed obesity } \\
\hline & \multicolumn{2}{|c|}{ total, $\mathrm{n}=156,948$} & \multicolumn{2}{|c|}{ boys, $\mathrm{n}=80,403$} & \multicolumn{2}{|c|}{ girls, $\mathrm{n}=76,545$} \\
\hline & yes & no & yes & no & yes & no \\
\hline $6-8$ & $1,118(2.3 \%)$ & 47,615 (97.7\%) & $495(2.0 \%)$ & $24,441(98.0 \%)$ & $623(2.6 \%)$ & $23,174(97.4 \%)$ \\
\hline 9-11 & $2,048(4.1 \%)$ & 48,207 (95.9\%) & $1,019(4.0 \%)$ & $24,707(96.0 \%)$ & $1,029(4.2 \%)$ & $23,500(95.8 \%)$ \\
\hline $12-14$ & $2,761(4.8 \%)$ & $55,199(95.2 \%)$ & $1,542(5.2 \%)$ & $28,199(94.8 \%)$ & $1,219(4.3 \%)$ & $27,000(95.7 \%)$ \\
\hline Total & $5,927(3.8 \%)$ & $151,021(96.2 \%)$ & $3,056(3.8 \%)$ & $77,347(96.2 \%)$ & $2,871(3.8 \%)$ & $73,674(96.2 \%)$ \\
\hline
\end{tabular}

tion. Among a non-clinical population, there was only a slight increment in the comorbidity of ADHD (assessed by the Strengths and Difficulties Questionnaire [19]) in obese students with BMI > 40 [20]. Studying potential mechanisms underlying the comorbidity between obesity and ADHD in clinical samples, Cortese et al. found that obese adolescents with bulimic behaviour [21] and obese adolescents with excessive daytime sleepiness [22] have a higher probability of presenting with ADHD symptoms (assessed by the Conners' Parent Rating Scale [23]).

Furthermore, overweight children in a community sample had higher scores on social problems, delinquent behaviour, and total problems (assessed by the Child Behaviour Checklist [24]) compared to non-overweight children [25]. Similarly, Stradmeijer et al. [26] showed that both parents and teachers reported more behaviour problems (assessed by the Child Behaviour Checklist and the Teacher Report Form [24]) in overweight children, particularly in pre-pubertal children (10-13 years).

Results concerning internalising problems (i.e. depressive symptoms and anxiety disorders) also show support for a relationship with obesity [27]. For example, Britz et al. [28] demonstrated high rates of mood and anxiety disorders (according to DSM-IV diagnoses) in a clinical group of 47 extremely obese adolescents. However, results based on a population-based sample of obese adolescents [28] as well as results based on a community survey [29] showed that obese adolescents and young adults did not suffer more frequently from mental disorders, such as anxiety or mood disorders (assessed by clinical evaluation). In a school-based sample of pre-adolescent children, overweight girls, but not overweight boys, manifested slightly more depressive symptoms (assessed by the Children's Depression Inventory, CDI [30]). This association was mediated by overweight concerns in girls [31]. Consistent with these findings, Gibson et al. [32] demonstrated an association between increasing (age- and gender-specific) BMI and higher levels of depression (assessed by the CDI) in primary school-aged children. Again, the increase in depression as BMI increased was stronger in girls than in boys. Prospective studies suggest a longitudinal association between childhood depression and female obesity [33-35].
Moreover, overweight adolescents in a weight management clinic were at greater risk of sleep problems (assessed by sleep questionnaires and behavioural assessment) than healthy controls [36]. Even among 5- and 6-year-old children, the prevalence of obesity decreases by duration of sleep, independent of other risk factors for childhood obesity [37].

The aim of our study was to analyse the prevalence of obesity and the association with comorbid mental disorders in a community-based sample of German children aged 6-14 years. Based on the literature, we expected that obesity would be associated with increased risk of externalising disorders (i.e. hyperkinetic disorders, conduct disorders), internalising disorders (i.e. anxiety disorders, depressive disorders), and sleep disorders as indicators of negative psychological effects. Moreover, we examined whether the association between obesity and increased risk of mental disorders would be modified by gender and age group. In contrast to previous studies, we recruited a large community-based sample $(\mathrm{n}=156,948)$. Secondly, rather than utilising self-reports, we operationalised obesity and comorbid disorders by physician diagnoses according to the ICD-10 classification [38].

\section{Material and Methods}

\section{Participants}

A total of $\mathrm{n}=156,948$ children $(51.2 \%$ male $)$ aged between 6 and 14 years (mean $=10.21, \mathrm{SD}=2.62)$ participated in this study (table 1$)$. To explore age effects, 3 age groups (categorised as 6- to 8-year-olds, 9- to 11-yearolds, and 12- to 14-year-olds) were examined. All participants were members of a German national health insurance named Gmünder ErsatzKasse (GEK).

Measurement of Obesity, Internalising Disorders, Externalising Disorders, and Sleep Disorders

In Germany, health insurance companies possess a large amount of insurance-related data due to the companies' administrative tasks. In the course of completing an invoice, physicians report patients' ICD-10 diagnoses (via the regional association of statutory health insurance physicians) to the patients' statutory health insurance company. The anonymous data of the GEK concerning the rates of several disorders, assessed by physician diagnoses (according to the ICD-10 international classification of diseases [38]; see table 2 for the corresponding ICD-10 codes) during the year 2004 was coded $(0 / 1=$ ICD-10 diagnosis absent/present). A similar study [39] indicates that the data of the GEK was comparable to data of a nationwide report from the Federal Statistical Office. It 
Table 2. List of studied disorders and corresponding ICD-10 codes and titles

\begin{tabular}{|c|c|c|}
\hline Studied disorders & Codes & Titles \\
\hline \multirow[t]{5}{*}{ Obesity } & E65 & localised adiposity \\
\hline & E66.0 & obesity due to excess calories \\
\hline & E66.2 & extreme obesity with alveolar hypoventilation \\
\hline & E66.8 & other obesity \\
\hline & E66.9 & obesity, unspecified \\
\hline \multicolumn{3}{|l|}{ Externalising disorders } \\
\hline \multirow[t]{4}{*}{ Hyperkinetic disorders } & F90.0 & disturbance of activity and attention \\
\hline & F90.1 & hyperkinetic conduct disorder \\
\hline & F90.8 & other hyperkinetic disorders \\
\hline & F90.9 & hyperkinetic disorders, unspecified \\
\hline \multirow[t]{3}{*}{ Conduct disorders } & F91 & conduct disorders \\
\hline & F91.3 & oppositional defiant disorder \\
\hline & F92 & mixed disorders of conduct and emotions \\
\hline \multicolumn{3}{|l|}{ Internalising disorders } \\
\hline \multirow[t]{9}{*}{ Anxiety disorders } & F93 & emotional disorders with onset specified to childhood \\
\hline & F93.0 & separation anxiety disorders of childhood \\
\hline & F93.1 & phobic anxiety disorder of childhood \\
\hline & F93.2 & social anxiety disorder of childhood \\
\hline & F93.8 & other childhood emotional disorders \\
\hline & F40 & phobic anxiety disorders \\
\hline & F40.00 & agoraphobia without history of panic disorder \\
\hline & F40.01 & panic disorder with agoraphobia \\
\hline & F41.0 & panic disorder \\
\hline \multirow[t]{3}{*}{ Depressive disorders } & $\mathrm{F} 32$ & depressive episode \\
\hline & F33 & recurrent depressive disorder \\
\hline & F34.1 & dysthymia \\
\hline \multirow[t]{3}{*}{ Sleep disorders } & G47.0 & insomnias \\
\hline & G47.2 & disorders of the sleep-wake schedule \\
\hline & G47.9 & sleep disorder, unspecified \\
\hline
\end{tabular}

is of note that payment is determined according to a medical fee schedule independent of reported ICD-10 diagnoses. These disorders include obesity, externalising disorders (consisting of hyperkinetic disorders and conduct disorders), internalising disorders (consisting of anxiety disorders and depressive disorders), sleep disorders, and stay in hospital (0/1 $=$ zero/at least 1 day).

\section{Statistical Analyses}

We evaluated $\chi^{2}$ statistics to test the simple association between physician-diagnosed obesity and comorbid disorders (externalising disorders, internalising disorders, sleep disorders, and stay in hospital). The odds ratio (OR) as a mean of evaluation of risk and its $95 \%$ confidence interval (CI) were computed for each comorbid disorder. Using logit-loglinear models, main effects and interaction effects of the 3 independent variables (physician-diagnosed obesity: presence 1 /absence 0 , gender, and age group: 6-8 years, $9-11$ years, $12-14$ years) on the dependent variables (i.e. externalising disorders, internalising disorders, sleep disorders, and stay in hospital; each dependent variable was categorised as presence 1/absence 0 ) were tested.

\section{Results}

\section{Descriptive Analyses}

In the total sample of 156,948 participants, the prevalence of physician-diagnosed obesity was $3.8 \%$. Of the participants, $6.5 \%$ were diagnosed with externalising disorders $(5.2 \%$ hy- perkinetic disorders, $2.0 \%$ conduct disorders), $2.8 \%$ with internalising disorders $(2.3 \%$ anxiety, $0.5 \%$ depressive disorders), $0.7 \%$ with sleep disorders, and $5.9 \%$ stayed at least 1 day in the hospital.

Neither age group, $\chi^{2}(2, \mathrm{n}=156,948)=0.26$, not significant (n.s.), nor physician-diagnosed obesity prevalence, $\chi^{2}(1$, $\mathrm{n}=156,948)=0.27$, n.s., differed significantly by gender. With age group there was an increase in physician-diagnosed obesity prevalence, $\chi^{2}(2, \mathrm{n}=156,948)=462.46, \mathrm{p}<0.001($ see table 1$)$.

\section{Associations between Obesity and Externalising Disorders,} Internalising Disorders, Sleep Disorders, and Stay in Hospital Physician-diagnosed obesity was significantly associated with each of the 4 disorders (table 3 ). The prevalence of externalising disorders $(10.1$ vs. $6.4 \%, \mathrm{OR}=1.64)$, internalising disorders $(5.2$ vs. $2.7 \%, \mathrm{OR}=2.00)$, sleep disorders $(1.3$ vs. $0.7 \%$, $\mathrm{OR}=1.87$ ), and stay in hospital ( $8.1 \mathrm{vs.} 5.8 \%$, OR = 1.44) was higher in children with obesity compared to children without physician-diagnosed obesity. To determine whether sleep disorders and stay in hospital are directly related to physiciandiagnosed obesity, we repeated the analyses with 143,846 children $(91.7 \%$ of the total sample; $49.6 \%$ male), without both physician-diagnosed internalising and externalising disorders. 
Table 3. Prevalence and odds ratio (OR) of externalising disorders, internalising disorders, sleep disorders, and stay in hospital by obesity
Table 4. Prevalence and odds ratio (OR) of externalising disorders, internalising disorders, sleep disorders, and stay in hospital by obesity and gender

\begin{tabular}{|c|c|c|c|c|c|c|c|}
\hline & \multicolumn{4}{|c|}{ Obesity } & \multirow[t]{3}{*}{$\chi^{2}$} & \multirow[t]{3}{*}{ OR } & \multirow[t]{3}{*}{$95 \%-\mathrm{CI}$} \\
\hline & \multicolumn{2}{|l|}{ no } & \multicolumn{2}{|l|}{ yes } & & & \\
\hline & $\mathrm{n}$ & $\%$ & $\mathrm{n}$ & $\%$ & & & \\
\hline Externalising disorders & 9,663 & 6.4 & 596 & 10.1 & $124.86 * * *$ & 1.64 & $1.50-1.78$ \\
\hline Hyperkinetic disorders & 7,787 & 5.2 & 427 & 7.2 & $48.24 * * *$ & 1.43 & $1.29-1.58$ \\
\hline Conduct disorders & 2,922 & 1.9 & 243 & 4.1 & $135.30^{* * *}$ & 2.17 & $1.90-2.48$ \\
\hline Internalising disorders & 4,011 & 2.7 & 307 & 5.2 & $135.77 * * *$ & 2.00 & $1.78-2.26$ \\
\hline Anxiety disorders & 3,432 & 2.3 & 230 & 3.9 & $64.71 * * *$ & 1.74 & $1.52-1.99$ \\
\hline Depressive disorders & 713 & 0.5 & 89 & 1.5 & $118.89 * * *$ & 3.21 & $2.57-4.01$ \\
\hline Sleep disorders & 1,026 & 0.7 & 75 & 1.3 & $28.12 * * *$ & 1.87 & $1.48-2.37$ \\
\hline Stay in hospital & 8,787 & 5.8 & 483 & 8.1 & $55.75 * * *$ & 1.44 & $1.31-1.58$ \\
\hline
\end{tabular}

Total sample: $\mathrm{n}=156,948$ (no obesity: $\mathrm{n}=151,021,96.2 \%$; yes obesity: $\mathrm{n}=5,927,3.8 \%$ ). See method section for definition of disorders. ${ }^{* *} \mathrm{p}<0.001$. Figures in italics indicate parameter estimates with $\mathrm{z}$-values $\geq 3.0(\mathrm{p}<0.01)$.

\begin{tabular}{|c|c|c|c|c|c|c|c|}
\hline & & \multicolumn{4}{|c|}{ Obesity } & \multirow[t]{3}{*}{ OR } & \multirow[t]{3}{*}{$95 \%-\mathrm{CI}$} \\
\hline & & \multicolumn{2}{|l|}{ no } & \multicolumn{2}{|l|}{ yes } & & \\
\hline & & $\mathrm{n}$ & $\%$ & $\mathrm{n}$ & $\%$ & & \\
\hline \multirow[t]{2}{*}{ Externalising disorders } & Boys & 7,209 & 9.3 & 419 & 13.7 & 1.55 & $1.39-1.72$ \\
\hline & Girls & 2,454 & 3.3 & 177 & 6.2 & 1.91 & $1.63-2.23$ \\
\hline \multirow[t]{2}{*}{ Hyperkinetic disorders } & Boys & 6,038 & 7.8 & 329 & 10.8 & 1.43 & $1.27-1.60$ \\
\hline & Girls & 1,749 & 2.4 & 98 & 3.4 & 1.45 & $1.18-1.79$ \\
\hline \multirow[t]{2}{*}{ Conduct disorders } & Boys & 2,041 & 2.6 & 155 & 5.1 & 1.97 & $1.67-2.33$ \\
\hline & Girls & 881 & 1.2 & 88 & 3.1 & 2.61 & $2.09-3.26$ \\
\hline \multirow[t]{2}{*}{ Internalising disorders } & Boys & 2,269 & 2.9 & 145 & 4.7 & 1.65 & $1.39-1.96$ \\
\hline & Girls & 1,742 & 2.4 & 162 & 5.6 & 2.47 & $2.09-2.91$ \\
\hline \multirow[t]{2}{*}{ Anxiety disorders } & Boys & 1,953 & 2.5 & 109 & 3.6 & 1.43 & $1.17-1.74$ \\
\hline & Girls & 1,479 & 2.0 & 121 & 4.2 & 2.15 & $1.78-2.60$ \\
\hline \multirow[t]{2}{*}{ Depressive disorders } & Boys & 392 & 0.5 & 42 & 1.4 & 2.74 & $1.99-3.77$ \\
\hline & Girls & 321 & 0.4 & 47 & 1.6 & 3.80 & $2.79-5.18$ \\
\hline \multirow[t]{2}{*}{ Sleep disorders } & Boys & 535 & 0.7 & 40 & 1.3 & 1.90 & $1.38-2.63$ \\
\hline & Girls & 491 & 0.7 & 35 & 1.2 & 1.84 & $1.30-2.60$ \\
\hline \multirow[t]{2}{*}{ Stay in hospital } & Boys & 4,886 & 6.3 & 264 & 8.6 & 1.40 & $1.23-1.60$ \\
\hline & Girls & 3,901 & 5.3 & 219 & 7.6 & 1.48 & $1.28-1.70$ \\
\hline
\end{tabular}

Total sample: $\mathrm{n}=156,948$ (no obesity boys: $\mathrm{n}=77,347$, yes obesity boys: $\mathrm{n}=3,056$; no obesity girls: $\mathrm{n}=73,674$, yes obesity girls: $\mathrm{n}=2,871$ ). See method section for definition of disorders. Figures in italics indicate parameter estimates with z-values $\geq 2.5$ $(\mathrm{p}<0.05)$.
Again, physician-diagnosed obesity was significantly associated with sleep disorders ( 0.9 vs. $0.5 \%, \mathrm{OR}=1.74,95-\mathrm{CI}=$ $1.29-2.35)$ and stay in hospital (7.4 vs. $5.4 \%$, OR $=1.40,95-\mathrm{CI}$ $=1.26-1.56)$.

Logit-loglinear analyses showed that, with regard to gender, the increased ORs were higher in girls with physician-diagnosed obesity compared to boys with physician-diagnosed obesity for externalising disorders $(\mathrm{OR}=1.91$ vs. 1.52$)$ and internalising disorders (especially anxiety, $\mathrm{OR}=2.15$ vs. 1.43 ) (table 4). According to age group, the increased OR was higher in 12- to 14-year-olds with physician-diagnosed obesity, compared to younger children with physician-diagnosed obesity, for internalising disorders (especially anxiety, $\mathrm{OR}=2.32$ vs. 1.59 and 1.43) (table 5). There was no significant three-way association between obesity, gender, and age group.

\section{Discussion}

In the present study, the association between obesity and mental disorders (assessed by physician diagnoses according to ICD-10) was investigated in a large community-based 
Table 5. Prevalence and odds ratio $(\mathrm{OR})$ of externalising disorders, internalising disorders, sleep disorders, and stay in hospital by obesity and age group

\begin{tabular}{|c|c|c|c|c|c|c|c|}
\hline & \multirow[t]{3}{*}{ Age group, years } & \multicolumn{4}{|c|}{ Obesity } & \multirow[t]{3}{*}{ OR } & \multirow[t]{3}{*}{$95 \%-\mathrm{CI}$} \\
\hline & & \multicolumn{2}{|l|}{ no } & \multicolumn{2}{|l|}{ yes } & & \\
\hline & & $\mathrm{n}$ & $\%$ & $\mathrm{n}$ & $\%$ & & \\
\hline \multirow[t]{3}{*}{ Externalising disorders } & $6-8$ & 3,254 & 6.8 & 111 & 9.9 & 1.50 & $1.23-1.83$ \\
\hline & $9-11$ & 3,624 & 7.5 & 233 & 11.4 & 1.58 & $1.37-1.82$ \\
\hline & $12-14$ & 2,785 & 5.0 & 252 & 9.1 & 1.89 & $1.65-2.16$ \\
\hline \multirow[t]{3}{*}{ Hyperkinetic disorders } & $6-8$ & 2,542 & 5.3 & 73 & 6.5 & 1.24 & $0.97-1.58$ \\
\hline & $9-11$ & 3,038 & 6.3 & 177 & 8.6 & 1.41 & $1.20-1.65$ \\
\hline & $12-14$ & 2,207 & 4.0 & 177 & 6.4 & 1.65 & $1.40-1.93$ \\
\hline \multirow[t]{3}{*}{ Conduct disorders } & $6-8$ & 1,056 & 2.2 & 51 & 4.6 & 2.11 & $1.58-2.81$ \\
\hline & $9-11$ & 997 & 2.1 & 87 & 4.2 & 2.10 & $1.68-2.63$ \\
\hline & $12-14$ & 869 & 1.6 & 105 & 3.8 & 2.47 & $2.01-3.04$ \\
\hline \multirow[t]{3}{*}{ Internalising disorders } & $6-8$ & 1,327 & 2.8 & 43 & 3.8 & 1.40 & $1.02-1.90$ \\
\hline & $9-11$ & 1,482 & 3.1 & 115 & 5.6 & 1.88 & $1.54-2.28$ \\
\hline & $12-14$ & 1,202 & 2.2 & 149 & 5.4 & 2.56 & $2.15-3.05$ \\
\hline \multirow[t]{3}{*}{ Anxiety disorders } & $6-8$ & 1,232 & 2.6 & 41 & 3.7 & 1.43 & $1.04-1.97$ \\
\hline & $9-11$ & 1,294 & 2.7 & 86 & 4.2 & 1.59 & $1.27-1.99$ \\
\hline & $12-14$ & 906 & 1.6 & 103 & 3.7 & 2.32 & $1.89-2.86$ \\
\hline \multirow[t]{3}{*}{ Depressive disorders } & $6-8$ & 114 & 0.2 & 3 & 0.3 & 1.12 & $0.36-3.53$ \\
\hline & $9-11$ & 244 & 0.5 & 34 & 1.7 & 3.32 & $2.31-4.76$ \\
\hline & $12-14$ & 355 & 0.6 & 52 & 1.9 & 2.97 & $2.21-3.98$ \\
\hline \multirow[t]{3}{*}{ Sleep disorders } & $6-8$ & 413 & 0.9 & 16 & 1.4 & 1.66 & $1.00-2.74$ \\
\hline & $9-11$ & 372 & 0.8 & 32 & 1.6 & 2.04 & $1.42-2.94$ \\
\hline & $12-14$ & 241 & 0.4 & 27 & 1.0 & 2.25 & $1.51-3.36$ \\
\hline \multirow[t]{3}{*}{ Stay in hospital } & $6-8$ & 3,033 & 6.4 & 91 & 8.1 & 1.30 & $1.05-1.62$ \\
\hline & $9-11$ & 2,635 & 5.5 & 154 & 7.5 & 1.41 & $1.19-1.67$ \\
\hline & $12-14$ & 3,119 & 5.7 & 238 & 8.6 & 1.58 & $1.37-1.81$ \\
\hline
\end{tabular}

Total sample: $n=156,948$ (no obesity 6 - to 8 -year-olds: $n=47,615$, yes obesity 6 - to 8 -year-olds: $n=1,118$; no obesity 9 - to 11-year-olds: $n=48,207$, yes obesity 9 - to 11 -year-olds: $n=2,048$; no obesity 12 - to 14 -year-olds: $n=55,199$, yes obesity 12 - to 14-year-olds: $n=2,761$ ). See method section for definition of disorders. Figures in italics indicate parameter estimates with z-values $\geq 2.1(\mathrm{p}<0.05)$. sample of children and young adolescents (age range 6 to 14 years). Overall, $3.8 \%$ of the sample was diagnosed as obese. There were no gender differences in obesity prevalence. However, there was an increase in obesity prevalence with age. While the findings regarding gender and age correspond with a representative German epidemiological survey [4], our prevalence of obesity was remarkably lower that that of the above mentioned survey (6.3\%). One possible explanation for this discrepancy is that in our study, in order to be diagnosed as obese, children must have consulted a physician. Therefore, within the subgroup of children not diagnosed as obese, there might be obese children who did not consult a doctor. On the other hand, there may be obese children who visited a physician to treat a medical problem that was not directly related to obesity. In some of these cases, it is conceivable that the physician may not have recorded the (additional) diagnosis of obesity. In this regard, prevalence rates of internalising disorders (e.g. anxiety: $2.3 \%$ in our study vs. approximately at least $10 \%$ in others $[40,41])$ are also underestimated, whereas prevalence rates for externalising disorders (a disorder that might be more likely to prompt someone to consult a physi- cian) nearly correspond to German epidemiological data (e.g. hyperkinetic disorders: $5.2 \%$ in our study vs. $3-4 \%$ in another study [42]). Thus, the reported effects might be underestimated to some degree. However, it seems worthwhile to utilise objective data in addition to subjective questionnaire data.

Is there an association between obesity and mental disorders? We found clear evidence for increased risks of externalising disorders $(\mathrm{OR}=1.64$; hyperkinetic disorders: $\mathrm{OR}=1.43$; conduct disorders: $\mathrm{OR}=2.17$ ), internalising disorders (overall $\mathrm{OR}=2.00$; anxiety $\mathrm{OR}=1.74$; depression $\mathrm{OR}=3.21$ ), sleep disorders $(\mathrm{OR}=1.87)$, and a stay in hospital $(\mathrm{OR}=1.44)$ for children with obesity when compared to children without physician-diagnosed obesity. However, due to the relatively small cell sizes of children with diagnosed obesity and sleep disorders or diagnosed obesity and depression, these two effects might be limited. Comparing the parameter estimates, the strongest association is found for internalising disorders: $5.2 \%$ of our sample diagnosed as obese met symptom criteria for anxiety and/or depressive disorders. This prevalence rate was twice as high than that of children classified as non-obese. Regarding the studied disorders as indicators of psychological 
ill-being, our results (based on objective data) are in line with previous community-based studies using subjective questionnaire data [13,25]. Our results (based on a large community sample) are also in line with mostly small clinical samples of obese children [17, 28, 36].

Moreover, gender and age group modified the results. Compared to boys, girls with obesity showed higher risks for externalising disorders and particularly internalising disorders (anxiety). In early adolescence (12- to 14-year-olds), the risk of internalising disorders (anxiety) was higher than in younger children with obesity. Research concerning gender and age differences that may influence the association between obesity and psychosocial well-being is rare. In line with our results, self-reported depressive symptoms or anxiety were most apparent in obese girls [31, 32, 43]. In a prospective study, Merten et al. [44] found that among adolescent females (but not males) the obesity status was associated with poorer psychosocial outcomes in young adulthood. Independent of obesity, studies on quality of life showed age and gender differences. Lower self-reported quality of life was associated with female gender and with increased age $>13$ years [9]. Our findings clearly suggest that the diagnostic investigation of obesity should include a thorough psychosocial evaluation. For obesity prevention and obesity intervention, it is important to understand comorbid health problems as well as potential interindividual influence factors (such as gender or age), both of which should be a focus in the respective programmes.

The present study supports the hypotheses of covariation of obesity and mental disorders (internalising disorders, externalising disorders, and sleep disorders) in a large communitybased sample of children and young adolescents. Generally, socioeconomic status is inversely related to adverse physical as well as mental health outcomes. Thus, children and adolescents with low socioeconomic status are more likely to be overweight and to be affected by psychological and behavioural difficulties [45]. Kohlmann and Weidner [46] demonstrated a moderating effect among young adults: BMI was positively associated with anxiety, but only among those with low socioeconomic status. Since our study lacks a valid measure of socioeconomic status, we are not able to determine the amount of variance of the association between obesity and (externalising) disorders that is explained by socioeconomic status. To analyse causal effects and to answer the question of whether obesity in childhood is related to the onset of mental disorders or (vice versa) whether mental disorders are a risk factor for developing obesity, more prospective longitudinal data is needed. There is preliminary evidence that obesity is a risk factor for developing depression in older adulthood [47]. However, prospective studies show that in adolescence, depression is associated with later weight gain and an increased risk of subsequent obesity [e.g. 33-35, 48].

\section{Acknowledgement}

This research was supported in part by a grant from the Gmünder ErsatzKasse (GEK) awarded to Carl-Walter Kohlmann. Thomas Schürholz is now at AnyCare GmbH, Stuttgart.

\section{Disclosure}

The authors declared no conflict of interest.

\section{References}

1 Haslam DW, James WPT: Obesity. Lancet 2005;366: 1197-1209.

2 World Health Organization: Obesity: Preventing and Managing the Global Epidemic. WHO Technical Report Series No 894. Geneva, WHO, 2000.

$\checkmark 3$ Deckelbaum RJ, Williams CL: Childhood obesity: the health issue. Obes Res 2001;9:S239-243.

$\checkmark 4$ Kurth BM, Schaffrath Rosario A: The prevalence of overweight and obese children and adolescents living in Germany. Results of the German Health Interview and Examination Survey for children and adolescents (in German). Bundesgesundheitsb Gesundheitsforsch Gesundheitsschutz 2007;50:736743.

5 Dietz WH: Health consequences of obesity in youth: childhood predictors of adult disease. J Pediatr 1998;101:518-525.

6 Must A, Jacques PF, Dallal GE, Bajema CJ, Dietz WH: Long-term morbidity and mortality of overweight adolescents. N Engl J Med 1992;327:1350 1355.

7 Hill AJ: Fed up and friendless? The Psychologist 2005;18:280-283.

8 Warschburger P: The unhappy obese child. Int J Obes (Lond) 2005;29:127-129.
9 Ravens-Sieberer U, Redegeld M, Bullinger M: Quality of life after in-patient rehabilitation in children with obesity. Int J Obes Relat Metab Disord 2001;25:63-65.

10 Schwimmer JB, Burwinkle TM, Varni JW: Healthrelated quality of life of severely obese children and adolescents. JAMA 2003:289:1813-1819.

11 Zeller MH, Modi AC: Predictors of health-related quality of life in obese youth. Obes Res 2006;14:122-130.

12 Warschburger P, Fromme C, Petermann F: Weightspecific quality of life in school children: validity of the GW-LQ-KJ (in German). Z Gesundheitspsychol 2004;12:159-166.

13 Williams J, Wake M, Hesketh K, Maher E, Waters E: Health-related quality of life of overweight and obese children. JAMA 2005;293:1-5.

14 Kurth BM, Ellert U: Perceived or true obesity: Which causes more suffering in adolescents? Findings of the German Health Interview and Examination Survey for Children and Adolescents (KiGGS). Dtsch Arztebl Int 2008;105:406-412.

15 American Psychiatric Association: Diagnostic and Statistical Manual of Mental Disorders DSM-IV, ed 4. Washington DC, American Psychiatric Association, 1995.
16 Vila G, Zipper E, Dabbas M, Bertrand C, Robert JJ, Ricour C, Mouren-Siméoni MC: Mental disorders in obese children and adolescents. Psychosom Med 2004;66:387-394.

17 Agranat-Meged AN, Deitcher C, Goldzweig G, Leibenson L, Stein M, Galili-Weisstub E: Childhood obesity and attention deficit/hyperactivity disorder: a newly described comorbidity in obese hospitalized children. Int J Eat Disord 2005:37:357-359.

18 Holtkamp K, Konrad K, Müller B, Heussen N, Herpertz S, Herpertz-Dahlmann B, Hebebrand $\mathrm{J}$ : Overweight and obesity in children with attention-deficit/hyperactivity disorder. Int J Obes Relat Metab Disord 2004:28:685-689.

19 Goodman R: Psychometric properties of the Strengths and Difficulties Questionnaire (SDQ). J Am Acad Child Adolesc Psychiatry 2001;40:1337-1345.

20 Rojo L, Ruiz E, Dominguez JA, Calaf M, Livianos L: Comorbidity between obesity and attention deficit/hyperactivity disorder: population study with 13-15-year-olds. Int J Eat Disord 2006;39:519-522.

21 Cortese S, Isnard P, Frelut ML, Michel G, Quantin L, Guedeney A, Falissard B, Acquaviva E, Dalla Bernardina B, Mouren MC: Association between symptoms of attention-deficit/hyperactivity disorder and bulimic behaviours in a clinical sample of severely obese adolescents. Int J Obes (Lond) 2007;31:340-346. 
22 Cortese S, Maffeis C, Konofal E, Lecendreux M, Comencini E, Agriman M, Vincenzi B, Pajno-Ferrara F, Mouren MC, Dalla Bernardina B: Parent reports of sleep/alertness problems and ADHD symptoms in a sample of obese adolescents. J Psychosom Res 2007;63:587-590.

23 Conners CK, Barkley RA: Rating scales and checklists for child psychopharmacology. Psychopharmacol Bull 1985;21:809-843.

24 Achenbach SA: Integrative Guide for the 1991 Child/4-18, YSR, and TRF Profiles. Burlington, VT, University of Vermont Department of Psychiatry, 1991.

25 Hwang JW, Lyoo IK, Kim BN, Shin MS, Kim SJ, Cho SC: The relationship between temperament and character and psychopathology in community children with overweight. J Dev Behav Pediatr 2006;27: 18-24.

26 Stradmeijer M, Bosch J, Koops W, Seidell J: Family functioning and psychosocial adjustment in overweight youngsters. Int J Eat Disord 2000;27:110114.

27 McElroy SL, Kotwal R, Malhotra S, Nelson EB, Keck PE, Nemeroff CB: Are mood disorders and obesity related? A review for the mental health professional. J Clin Psychiatry 2004;65:634-651.

28 Britz B, Siegfried W, Ziegler A, Lamertz C, Herpertz-Dahlmann BM, Remschmidt H, Wittchen HU, Hebebrand J: Rates of psychiatric disorders in a clinical study group of adolescents with extreme obesity and in obese adolescents ascertained via a population based study. Int J Obes Relat Metab Disord 2000;24:1707-1714.

-29 Lamertz CM, Jacobi C, Yassouridis A, Arnold K, Henkel AW: Are obese adolescents and young adults at higher risk for mental disorders? A community survey. Obes Res 2002;10:1152-1160.

30 Kovacs M: The Children's Depression Inventory (CDI). Manual. Toronto, Ontario, Multi Health Systems Inc., 1992.
31 Erickson SJ, Robinson TN, Haydel KF, Killen JD: Are overweight children unhappy? Body mass index, depressive symptoms, and overweight concerns in elementary school children. Arch Pediatr Adolesc Med 2000;154:931-935.

32 Gibson LY, Byrne SM, Blair E, Davis EA, Jacoby P, Zubrick SR: Clustering of psychosocial symptoms in overweight children. Aust N Z J Psychiatry 2008;42:118-125.

33 Pine DS, Cohen P, Brook J, Coplan JD: Psychiatric symptoms in adolescence as predictors of obesity in early adulthood: a longitudinal study. Am J Public Health 1997;87:1303-1310.

34 Goodman E, Whitaker RC: A prospective study of the role of depression in the development and persistence of adolescent obesity. Pediatrics 2002;110: 497-504.

35 Hasler G, Pine DS, Kleinbaum DG, Gamma A, Luckenbaugh D, Ajdacic V, Eich D, Rössler W, Angst J: Depressive symptoms during childhood and adult obesity: the Zurich Cohort Study. Mol Psychiatry 2005;10:842-850.

36 Beebe DW, Lewin D, Zeller M, McCabe M, MacLeod K, Daniels SR, Amin R: Sleep in overweight adolescents: shorter sleep, poorer sleep quality, sleepiness, and sleep-disordered breathing. J Pediatr Psychol 2007;32:69-79.

37 von Kries R, Toschke AM, Wurmser H, Sauerwald T, Koletzko B: Reduced risk for overweight and obesity in 5- and 6-y-old children by duration of sleep: a cross-sectional study. Int J Obes Relat Metab Disord 2002;26:710-716.

38 World Health Organization: ICD-10: International Statistical Classification of Diseases and Related Health Problems: Tenth Revision (electronic resource). WHO, 2005.

39 Bichler KH, Strohmaier WL, Eipper E, Lahme S: Das Harnsteinleiden. Berlin, Lehmanns Media, 2007.
40 Essau CA, Conradt J, Petermann, F: Frequency, comorbidity, and psychosocial impairment of anxiety disorders in adolescents. J Anxiety Disord 2000;14: 263-279.

41 Federer M, Herrle J, Margraf, J, Schneider S: Separation anxiety and agoraphobia in 8-year-old children (in German). Prax Kinderpsychol Kinderpsychiatr 2000;49:83-96.

42 Blanz B: Hyperkinetische Störung, ADHD, Hyperaktivität. Kinderärztl Prax 2001;72:5-8.

43 Young-Hyman D, Tanofsky-Kraff M, Yanovski SZ, Keil M, Cohen ML, Peyrot M, Yanovski JA Psychological status and weight-related distress in overweight or at-risk-for-overweight children. Obesity 2006;14:2249-2258

Obesity 2006; $14: 2249-2258$.
Merten MJ, Wickrama KAS, Williams AL: Adolescent obesity and young adult psychosocial outcomes: gender and racial differences. J Youth Adolesc 2008;37:1111-1122.

45 Lampert T, Kurth BM: Socioeconomic status and health in children and adolescents. Results of the German Health Interview and Examination Survey for Children and Adolescents (KiGGS). Dtsch Arztebl Int 2007;104:2944-2949.

46 Kohlmann CW, Weidner G: Emotional correlates of body weight: the moderating effects of gender and family income. Anxiety Stress Coping 1996;9:357-367.

47 Roberts RE, Deleger S, Strawbridge WJ, Kaplan GA: Prospective association between obesity and depression: evidence from the Alameda County Study. Int J Obes 2003;27:514-521.

48 Pine DS, Goldstein RB, Wolk S, Weissman MM: The association between childhood depression and adulthood body mass index. Pediatrics 2001;107: 1049-1056. 